\title{
The adult Bullard laryngoscope in paediatric patients
}

Purpose: The adult Bullard laryngoscope (BL) is effective in managing both normal and abnormal ainways. Although its name implies use in the adult population, its size does not preclude its use in paediatric patients. Thus we evaluated whether the adult BL could be used in the paediatric population and whether its efficacy was related to age, weight, or height.

Methods: Fify consecutive patients, between the ages of I and 10 years and scheduled for general anaesthesia, were examined. Exclusion criteria included obvious craniofacial abnormalities or indications for rapid sequence intubation. All patients had intravenous access secured before laryngoscopy. The laryngeal view, attempts at intubation, time to intubation and the reason for any difficulty with intubation were reconded. Correlation was then sought relating attempts and time to intubation with age, weight and height.

Results: Mean time to intubation was $38 \pm 13 \mathrm{sec}$. Multiple attempts occurred most frequently because of right aryepiglottic fold contact or anterior vocal cord contact. The latter appears to be unique to the adult BL use in the paediatric population. No relationship was found between the time to intubation and age, height, or weight. Four tracheas, all in patients $<38$ mo, could not be intubated with the BL after four attempts.

Conclusion: The adult BL appears to be an effective alternative tool in the management of the normal paediatric ainway.

Objectif : Le laryngoscope de Bullard (LB) pour adulte permet d'aborder avec efficacité les voies aériennes normales et anormales. Bien que son nom soit associé aux adultes, sa taille n'exclut pas son usage pédiatrique. Nous avons done déterminé si le LB adulte pouvait être utilisé chez les enfants et si son efficacité dépendait de l'åge, du poids ou de la taille du sujet.

Méthodes : Cinquante patients âgés de 1 à 10 ans et programmés successivement pour une anesthésie générale ont participé à l'étude. Les critères d'exclusion comprenaient les malformations craniofaciales évidentes ou les indications usuelles d'une intubation à séquence rapide. La laryngoscopie était toujours précédée de l'installation d'un accès veineux. La visualisation du larynx, le nombre de tentatives, la durée de lintubation et les causes de difficultés ont été enregistrées. On a recherché la corrélation entre les tentatives et la durée de l'intubation, d'une part, et l'âge, le poids et la taille, d'autre part.

Résultats : La durée moyenne de l'intubation était de $38 \pm 13 \mathrm{~s}$. Les tentatives multiples survenaient le plus souvent parce que la lame butait sur le repli aryépiglottique droit ou sur les cordes vocales antérieures. Cette demière constatation semble unique au LB adulte utilisé en pédiatrie. II n'y avait pas de relation entre la durée de l'intubation et l'age, le poids ou la taille du sujet. Quatre patients de moins de 38 mois n'ont pu être intubés après quatre tentatives.

Conclusion : Le LB adulte permet d'aborder les voies aériennes de l'enfant normal avec efficacité.

From the Department of Anesthesiology, Baystate Medical Center, Tufts University School of Medicine, 759 Chestnut Street Springfield, MA 01199.

Presented, in part, at the Postgraduate Assembly of the New York Anesthesia Sociery, New York, NY, December 1996. Address correspondenee to: Neil Roy Connelly MD; Phone: 413-784-4325; Fax: 413-784-5349. Accepted for publication June 1, 1997. 
$\mathrm{T}$

HE Bullard laryngoscope (BL) is an effective alternative tool in securing both normal and abnormal airways. ${ }^{1-3}$ Presently, the manufacturer (Circon ACMI, Stamford, $\mathrm{CT}$ ) produces three sizes of scopes: paediatric (newborn to two years): paediatric long (newborn to 10 $y r)$ : and adult. The adult BL has the following dimensions: width: $2.5 \mathrm{~cm}$; blade thickness: $0.64 \mathrm{~cm}$; and internal radius of curvature: 1.32 in. The paediatric $\mathrm{BL}$ has the following dimensions: width: $1.3 \mathrm{~cm}$; blade thickness: $0.64 \mathrm{~cm}$; and internal radius of curvature: $0.74 \mathrm{in}$. The initial design specifications of the BL (paediatric and adult) were derived from mannequin studies with minor alterations following field trials. ${ }^{a}$ Recommendations regarding the appropriate size scope for a particular age group have not been examined experimentally. Therefore, we attempted to define whether the adult model is effective in the management of the paediatric airway and also whether there is a lower age limit to its effectiveness.

\section{Methods}

Following institutional review board approval, 50 consecutive paediatric patients scheduled for elective general anaesthesia requiring tracheal intubation were evaluated. Exclusion criteria included indication for rapid sequence induction and obvious craniofacial abnormalities. All the laryngoscopies were performed by an anesthesiologist experienced in the use of the $\mathrm{BL}$ in adults, but with no experience with its use in children.

Anaesthesia was induced and maintained with sevoflurane by mask. Following induction of general anaesthesia, intravenous access was secured. When an adequate depth of anaesthesia had been obtained, laryngoscopy was performed with the BL with the preformed stylet which is standard with the BL. The tracheal tube was loaded on the stylet and the stylet was inserted in its attachment port on the BL before laryngoscopy. The set-up was kept warm by wrapping it in a warmed blanket. The use of muscle relaxants to facilitate intubation was not standardized and was left to the discretion of the anesthesiologist. If vocal cord abduction was encountered during laryngoscopy despite an adequate depth of anaesthesia, vecuronium was administered. End-points examined included success of intubation, time required to intubate, laryngeal view at intubation, and the number of attempts at passing the tracheal tube. The time to intubate was defined as the time from the last mask ventilation to the re-establishment of ventilation via the endotracheal tube. This was

\footnotetext{
Personal communication, J Roger Bullard, MD
}

confirmed by the presence of end-tidal $\mathrm{CO}_{2}$. The laryngeal view through the $\mathrm{BL}$ was classified on a scale from I to IV according to Cormack. ${ }^{4}$ An attempt at intubation was defined as advancement of the tracheal tube until it entered the trachea or until it had to be withdrawn up the stylet before further manipulation of the scope could be performed. These manipulations did not require removal of the $\mathrm{BL}$ from the mouth of the patient but, rather, they involved subtle changes of head position in order to alter the tracheal tube's approach to the glottis as it left the preformed stylet. Thus, time to intubate reflects the time required to pick up the scope, place it in the child's mouth, identify the glottis, manipulate the scope within the child's mouth, advance the tube, and resume ventilation. Patients who had complications during laryngoscopy, such as incomplete paralysis, had the BL removed from the oral cavity, and mask ventilation reestablished. In patients in whom such difficulties arose, the time to intubation is reflected by the time of the uncomplicated second attempt. A failure was defined as inability to place the endotracheal tube after four attempts. Reasons for multiple attempts were recorded.

Correlation was performed between age, height, and weight and the time and the number of attempts required to intubate the trachea. Data is presented as mean $\pm S D$. Significance was determined at the $P<0.05$ level.

\section{Results}

The mean age of the patients studied was $42 \pm 25$ mo (range: 12-117 mo). The mean weight of the patients studied was $17 \pm 8 \mathrm{~kg}$ (range: $8-43 \mathrm{~kg}$ ). The mean height of the patients studied was $99 \pm 19 \mathrm{~cm}$ (range: $71-150 \mathrm{~cm}$ ). In the patients whose tracheas were successfully intubated, the mean time to intubation was $38 \pm 13 \mathrm{sec}$ (range: $23-78 \mathrm{sec}$ ). The mean number of attempts at intubation was $2 \pm 1$ (range: $1-4$ ). There were four patients in whom intubation could not be performed within four attempts; in all these patients intubation was easily achieved using a standard laryngoscope (all tracheas were intubated with a Mac 2 laryngoscope and all had Cormack I views through this scope). The demographic data on these four patients are as follows: $35 \mathrm{mo}, 15 \mathrm{~kg}, 96 \mathrm{~cm} ; 29 \mathrm{mo}, 15 \mathrm{~kg}$, $91 \mathrm{~cm} ; 16 \mathrm{mo}, 11 \mathrm{~kg}, 74 \mathrm{~cm}$; and $38 \mathrm{mo}, 13 \mathrm{~kg}, 99 \mathrm{~cm}$.

Fifty-four percent $(27 / 50)$ required more than one attempt at intubation (Table). There was no correlation between the age $\left(r^{2}=0.002\right.$; Figure 1$)$, weight $\left(r^{2}=0.01\right.$; Figure 2$)$, or height $\left(r^{2}=0.003\right)$ and the time for intubation. There was no correlation between age $\left(r^{2}=0.02\right)$, weight $\left(r^{2}=0.04\right)$, or height $\left(r^{2}=0.01\right)$ and the number of attempts at intubation. 
TABLE Causes of multiple intubation attempts. The total number is greater than 27 since in one patient, aryepiglottic fold contact was encountered during one attempt, and on a subsequent attempt, anterior vocal cord contact was made.

\begin{tabular}{lcc}
\hline & Number of patients & Incidence \\
\hline Anterior vocal cord contact & 13 & $26 \%$ \\
Aryepiglotic fold contact & 9 & $18 \%$ \\
Insufficient muscle relaxant & 4 & $8 \%$ \\
Fogged Bullard laryngoscope & 1 & $2 \%$ \\
Angle of stylet too steep & 1 & $2 \%$ \\
\hline
\end{tabular}

\section{Discussion}

Many surgical operating rooms which are used to care for children primarily treat adults. Much of the equipment used in these hospitals has been designed for adults. We found that the adult BL could be used successfully to intubate the tracheas of children despite the large size of the adult BL. Although we were unable to demonstrate the effectiveness of the $\mathrm{BL}$ decreasing below a particular age, weight or height, the four failures were all in children $<38$ mo. This may represent a trend which this study at its present size could not detect.

It has been reported that the mean time for visualization of the larynx in children using the paediatric $\mathrm{BL}$ was $12.6 \mathrm{sec},{ }^{1}$ and in adults using the adult BL was 9.5 $\sec ^{2}$ (in the adults, there was a mean time for intubation of $46.1 \mathrm{sec}$ in one study ${ }^{2}$ and $39 \mathrm{sec}$ in another $\left.{ }^{3}\right)$. It should be noted that in the present study the time to intubation was defined as the time from last mask ventilation to the re-establishment of ventilation via the ETT as confirmed by the presence of end-tidal $\mathrm{CO}_{2}$. Previous studies did not clearly define endpoint criteria making comparisons difficult to interpret. Our definition of "time for intubation" might lead to over estimation of the time required. Given the variability in the definition, our results are similar to previous reports using the adult and paediatric BL.

Use of the BL in adults leads to the common difficulty of right aryepiglottic fold contact ${ }^{5}$ preventing advancement of the tube into the trachea. This arises due to the design of the BL stylet. The standard stylet positions the tube on the right side of the BL. The stylet is angled towards the left at its distal end in order to move the tube midline towards the glottis. However, the stylet can position the tube from too far left of the glottis or too far right and hit the right aryepiglottic fold. In the children, the size of the adult BL usually limits rotational ability in overcoming aryepligottic fold contact. Anterior vocal cord contact appears to be unique to the $\mathrm{BL}$ use in children and

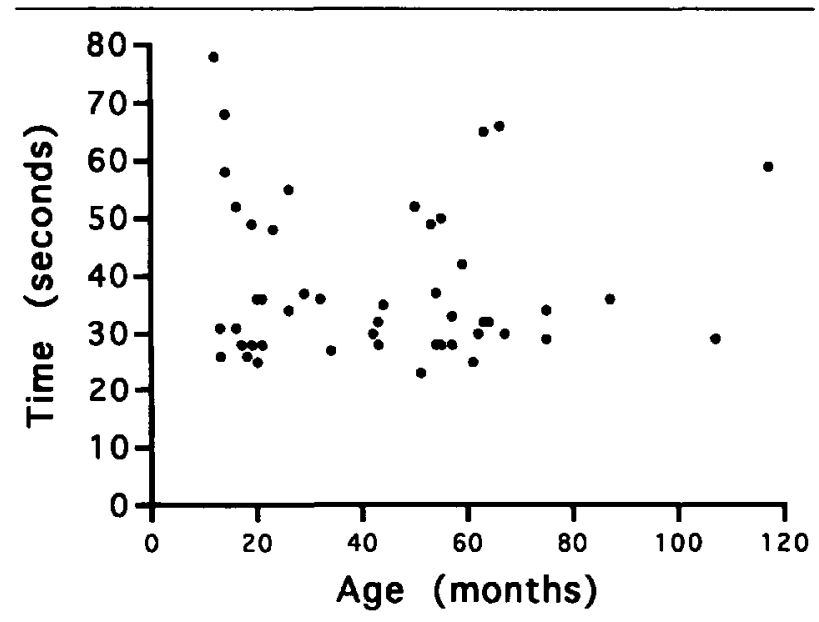

FIGURE 1 Correlation between age and the time to intubation. $\mathrm{R}^{2}=0.002 ; P: \mathrm{NS}$.

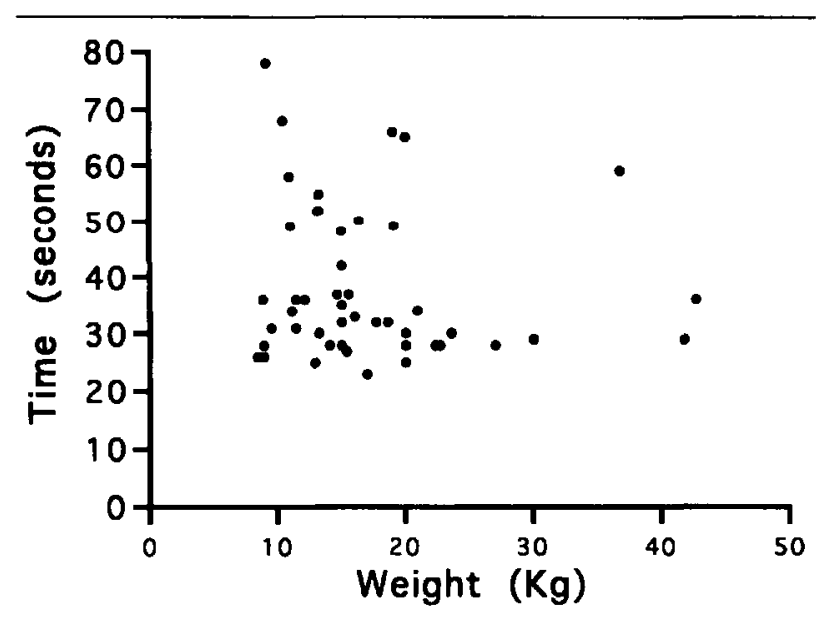

FIGURE 2 Correlation between weight and time to intubation. $\mathrm{R}^{2}=0.01 ; P: \mathrm{NS}$.

results from the smaller tube failing to deflect the stylet inferiorly as the tube is advanced (which occurs when larger ETTs are used in adults) and the shorter distance between the end of the laryngoscope and the vocal cords. We believe that a reduced angle at the tip of the intubating stylet would have reduced the number of episodes of right aryepiglottic fold contact. Such a modification in the stylet has been described to avoid this problem in adults. ${ }^{6}$ The design of the paediatric and paediatric long $\mathrm{BL}$ results in a substantially shorter laryngoscope, which should retain the relative position of the tip of the blade to the glottic opening that is seen with the adult model. This should provide increased room for the manipulation of the 
laryngoscope and ETT to avoid unwanted laryngeal contact. Further comparison between the adult model with a modified stylet and the paediatric models with respect to their ability to decrease the incidence of these difficulties could be topics for further studies. A final caveat is that the population in this study included no children with craniofacial abnormalities, and the results may not be applicable to such patients.

We have shown that the adult $\mathrm{BL}$ can be used to facilitate tracheal intubation in children $>12 \mathrm{mo}$, who have normal airways. We were unable to determine an age-related increase in the time required or the number of attempts required for intubation. The BL continues to display a tendency to contact the right aryepiglottic fold and, particularly in children, to contact the anterior aspect of the vocal cords. Both lead to multiple attempts at intubation. The four failures all occurred in children $<38$ mo. Further studies with more patients are required to compare the adult BL with the specific paediatric Bullard models and with standard laryngoscopes in children with normal and abnormal airways. Realizing that a majority of hospitals may have only advanced adult airway equipment, we feel that an anaesthetist skilled in the use of the BL, who is managing a paediatric airway, should not overlook the adult $\mathrm{BL}$ in its management.

\section{References}

1 Borland LM, Casselbrant $M$. The Bullard laryngoscope. A new indirect oral laryngoscope (pediatric version).

Anesth Analg 1990; 70: 105-8.

2 Cobn AI, Zornow $M H$. Awake endotracheal intubation in patients with cervical spine disease: a comparison of the Bullard laryngoscope and the fiberoptic bronchoscope. Anesth Analg 1995; 81: 1283-6.

3 Cooper SD, Benumof JL, Ozaki GT. Evaluation of the Bullard laryngoscope using the new intubating stylet: comparison with conventional laryngoscopy. Anesth Analg 1994; 79: 965-70.

4 Cormack RS, Lehane J. Difficult tracheal intubation in obstetrics. Anaesthesia 1984; 39: 1105-11.

5 Katsnelson T, Farcon E, Schwalbe SS, Badola R. The Bullard laryngoscope and the right aryetnoid (Letter). Can J Anaesth 1994; 41: 552-3.

6 Crosby ET. Techniques using the Bullard laryngoscope (Letter). Anesth Analg 1995; 81: 1314-5. 